\title{
PERANCANGAN MODEL BASIS DATA SISTEM OPERASIONAL BERBASISKAN CUSTOMER RELATIONSHIP MANAGEMENT
}

\author{
Tanty Oktavia \\ Information Systems Department, School of Information Systems, Binus University \\ Jl. K.H. Syahdan No. 9, Palmerah, Jakarta Barat 11480 \\ toktavia@binus.edu
}

\begin{abstract}
Data is a very important asset for a company since it describes the company's running processes. Database as a part of the information system components provides a big influence in helping data integration in a company. Therefore, we need a system which can facilitate the availability of data to be processed and used as needed, This study takes a company engaged in the sale of bike and spare parts, namely PT TDI, as the object of the study. At this time, PT TDI uses an integrated system in helping the company's operations. Along with the vision and mission, PT TDI intends to build a new operating system by applying the concept of Customer Relationship Management (CRM) which is believed to assist the company in maintaining relationships with customers using web-based platform. It aims to facilitate interaction with customers so that it can be done anytime and anywhere. This study implements the database design life cycle adjusted to the component aspects of CRM. The result achieved is a model that combines database CRM systems that can help companies improve relationships with customers.
\end{abstract}

Keywords: database, customer relationship management, web

\begin{abstract}
ABSTRAK
Data merupakan asset yang sangat penting bagi perusahaan karena menggambarkan seluruh proses yang berjalan. Database sebagai bagian dalam komponen sistem informasi memiliki andil yang cukup besar dalam membantu mengintegrasikan data-data dalam suatu perusahaan. Oleh karena itu, dibutuhkan suatu sistem yang dapat memfasilitasi keberadaan data agar dapat diolah dan digunakan sesuai dengan kebutuhan. Penelitian ini mengambil satu contoh objek perusahaan yang bergerak dalam bidang penjualan sepeda dan sparepart-nya, yaitu PT TDI. Pada saat ini, PT TDI menggunakan sistem terintegrasi dalam membantu operasional perusahaan. Seiring dengan visi dan misi perusahaan ingin menjadi salah satu perusahaan terbesar dalam bidang sepeda ini, PT TDI berkeinginan untuk membangun suatu sistem operasional baru dengan menerapkan konsep Customer Relationship Management (CRM) yang diyakini dapat membantu perusahaan dalam menjaga hubungan dengan pelanggan menggunakan web based platform. Hal ini bertujuan untuk memudahkan interaksi perusahaan dengan pelanggan agar dapat dilakukan kapanpun dan di manapun. Penyusunan penelitian ini menggunakan metode perancangan dalam database life cycle yang disesuikan dengan aspek komponen dalam CRM. Hasil yang dicapai adalah model database yang mengkombinasikan sistem CRM yang dapat membantu perusahaan dalam meningkatkan hubungan baik dengan pelanggan.
\end{abstract}

Kata kunci: database, customer relationship management, web 


\section{PENDAHULUAN}

Database Management Systems (DBMS) merupakan salah satu sistem software yang kompleks dan cukup kritikal karena DBMS telah menjadi bagian dalam sistem penunjang perusahaan di segala bidang unit usaha. Hal ini membuat database berperan menjadi konsep yang cukup berpengaruh dalam ilmu komputer dan terus dilakukan inovasi terhadap perkembangannya. Pengertian database sendiri menurut (Belanger \& Slyke, 2012) merupakan kumpulan data yang terorganisir yang dapat menyimpan informasi dalam bentuk yang bervariasi, seperti dalam bentuk text, angka, dokumen, gambar, dan video. Sebagai langkah dalam memudahkan untuk merepresentasikan objek dari suatu sistem database, secara konseptual pengguna dapat menggunakan data model yang tersusun menggunakan konsep dasar dan notasi.

Data model memuat tiga komponen, di antaranya struktural, operasional manipulative, dan constraint integritas yang menjaga kesesuaian data; sebagai bagian dalam pembentukan database. Sampai saat ini, banyak sekali pengelompokan kategori data model yang berkembang dan digunakan oleh perusahaan/organisasi, di antaranya object based data model (entity relationship, semantic, functional, object oriented), record based data model (relational data model, network data model, hierarchical data model), dan physical data model.

Sebuah DBMS tersusun dari beberapa komponen yang saling berkolaborasi dalam mendukung pengeksekusian query yang dilakukan oleh pengguna dalam suatu sistem database. Jika diilustrasikan dalam suatu transaksi, ketika seorang pengguna mengakses suatu tombol dalam situs web, seperti ketika ingin masuk ke dalam email, pengguna akan memasukan username dan password kemudian menekan tombol login. Tombol login ini yang akan mengeksekusi query yang telah terdefinisi sebelumnya pada aplikasi. Kemudian akan dilakukan parsing yang bertujuan dalam melakukan pengecekan secara semantik maupun secara sintaks yang didefinisi pada query yang terbentuk. Selanjutnya, komputer akan mengaktifkan API untuk menghubungkan dengan Client Communication Manager dari DBMS. Setelah itu barulah seluruh eksekusi dilakukan, sesuai dengan utilitas yang tersedia dalam komponen DBMS, seperti DML Preprocessor, Query Processor, DDL Compiler, Program Object Code, Database Manager, dan Dictionary Manger, dan lain sebagainya seperti pada Gambar 1.

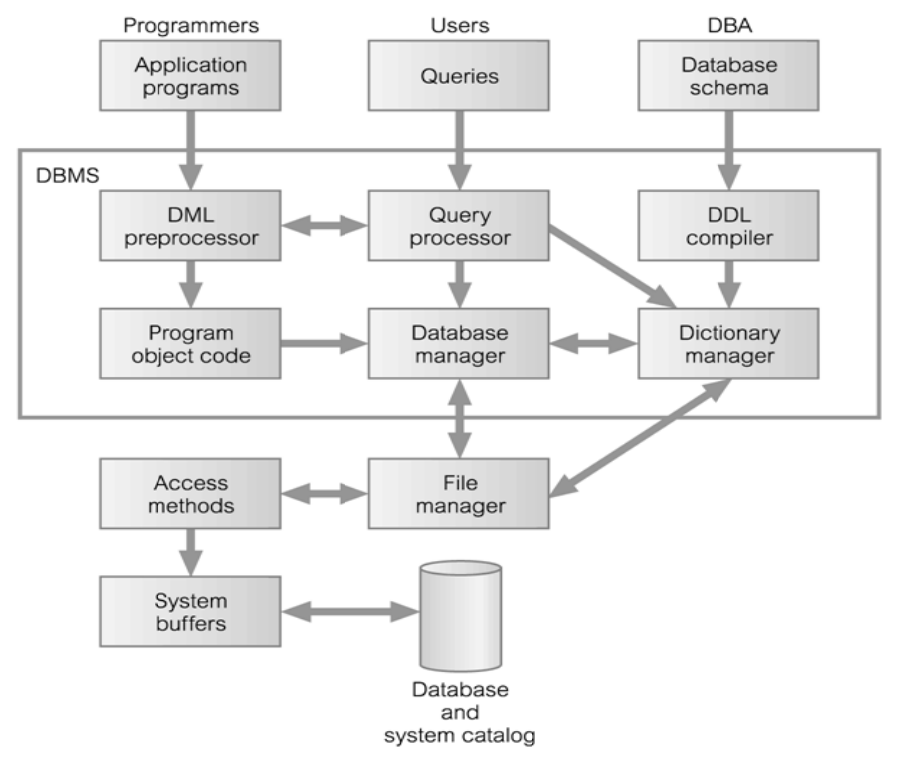

Gambar 1 Komponen utama DBMS (Connolly \& Begg, 2010) 
Operasional yang berlangsung pada PT TDI sudah dilakukan secara terintegrasi menggunakan sistem terpusat. Semua data yang dihasilkan dalam tiap transaksi telah tersimpan semua dalam bentuk yang sistematis. Hal ini berdampak cukup positif dalam kelangsungan operasional PT TDI. Semakin tingginya persaingan yang terjadi dalam industri mendorong perusahaan semakin aware terhadap relasi yang dibangun dengan customer. Customer yang diyakini sebagai roda penggerak perusahaan dalam menjalankan bisnisnya harus tetap dijaga agar tidak mudah beralih ke perusahaan pesaing. Jika seorang customer memutuskan untuk beralih ke perusahaan lain, diyakini perlu usaha yang cukup keras bagi perusahaan untuk menemukan customer baru yang berpotensi dalam melakukan transaksi di dalam perusahaan. Tidak sedikit biaya dan waktu yang akan dikeluarkan untuk menyelesaikan masalah tersebut. Dari pemikiran tersebut, muncul sebuah ide untuk mengkombinasikan konsep CRM dalam pelayanan transaksi perusahaan. Dalam konsep CRM ini, semua operasional akan difokuskan pada Customer sebagai pusat. Hal ini dapat dilakukan dengan mengidentifikasi kebutuhan dari customer, serta menjaga hubungan baik dengan customer yang dapat diwujudkan dalam bentuk memberikan dukungan ataupun memfasilitasi customer experiences dengan mengintegrasikan dalam kegiatan marketing, sales, serta dukungan terhadap customer melalui kegiatan pengukuran dan evaluasi dari proses knowledge sharing. Dengan begitu, customer akan merasa memiliki keterikatan batin dengan perusahaan dan sulit untuk beralih ke perusahaan lain.

Konsep CRM ini telah berkembang cukup lama, dan telah banyak diterapkan oleh perusahaanperusahaan terkenal, seperti Starbuck, Amazon, dan perusahaa lainnya. Konsep CRM yang diusulkan pada PT TDI ini akan dijalankan menggunakan infrastruktur internet sebagai pondasi dasar pelaksanaan mekanisme sistemnya karena disadari internet telah menjadi bagian dalam kehidupan sehari-hari. Banyak keuntungan yang diperoleh perusahaan dengan menggunakan internet sebagai bagian dari pelaksanaan sistem perusahaan, di antaranya (Chaffey, 2000): (1) mengurangi biaya kegiatan pemasaran dan penjualan dapat dilakukan dengan menggunakan media elektronik, sehingga dapat mengurangi biaya-biaya penunjang, seperti kertas dan iklan; (2) keuntungan kompetitif - jika suatu perusahaan mengenalkan inovasi baru sebelum pesaingnya mengeluarkan hal yang sama dan inovasi tersebut dapat diterima oleh customer, perusahaan tersebut akan unggul dalam pasar sampai pesaing berhasil menyamakan kekuatan dengan perusahaan; (3) peningkatan komunikasi penggunaan internet dapat meningkatkan komunikasi dengan customer, karyawan, pemasok, dan distributor karena komunikasi dapat dilakukan lebih intens lagi; (4) kontrol - internet dan intranet menyediakan penyelidikan pemasaran melalui perilaku customer; (5) peningkatan pelayanan terhadap customer dengan meningkatkan operasional internal, seperti memperhatikan stok barang dan mendengarkan segala kritik dan saran yang datang dari customer.

Mengkolaborasikan konsep CRM dengan operasional yang berjalan dalam suatu perusahaan/organisasi bukanlah pekerjaan yang mudah karena proses ini akan menyeimbangkan kepentingan perusahaan dengan pemenuhan kebutuhan dari sisi customer (Motiwalla \& Thompson, 2009). Penelitian ini lebih difokuskan pada penggunaan relational data model. Konsep relational database management system merupakan salah satu bentuk struktur model yang sudah matang dan paling banyak diimplementasikan saat ini. Sistem ini dapat ditemukan pada berbagai core sistem infrastruktur aplikasi, seperti e-commerce, medical records, billing, human resources, payroll, dll. (Hellerstein, Stonebraker, \& Hamilton, 2007). Pada konsep relational database ini, masing-masing data akan diklasifikasikan menjadi satu entitas/tabel yang saling terhubung satu sama lain. Sistem relational menyediakan sistem penyimpanan data pada setiap transaksi yang dilakukan.

\section{METODE}

Penelitian yang dilakukan bertujuan untuk mengintegrasikan database yang dapat mendukung pelaksanaan operasional, sehingga mengacu pada beberapa metode. Pertama adalah analisis. Proses 
analisis dlakukan melalui beberapa tahapan, yaitu: (1) observasi yang dilakukan dalam proses yang berjalan pada objek penelitian, yaitu PT TDI; (2) analisis terhadap pengumpulan data dari hasil temuan selama observasi; (3) mengidentifikasikan kebutuhan informasi dalam mendukung perancangan sistem CRM; (4) memetakan fase CRM dengan kegiatan operasional perusahaan. Metode kedua yaitu perancangan. Perancangan dilakukan untuk model sistem yang dapat mendukung pelaksanaan operasional CRM dalam perusahaan dengan memfokuskan pada pembentukan database sebagai media penyimpanan data. Perancangan model database mengacu pada database life cycle (Connolly \& Begg, 2010), yang membagi menjadi beberapa tahapan, yaitu: database planning, system definition, requirement collection and analysis, database design, DBMS selection, application design, prototyping, implementation, data conversion and loading, testing, dan operational maintenance.

\section{HASIL DAN PEMBAHASAN}

Implementasi CRM merujuk pada beberapa fase yang dapat mendukung perusahaan dalam menciptakan dan menjalin hubungan baik dengan para customer-nya. Fase-fase tersebut dijabarkan sebagai berikut (Kalakota \& Robinson, 2001):

Fase pertama adalah mendapatkan customer baru (acquire). Untuk memperoleh customer baru, pada sistem aplikasi perlu disediakan modul register, promosi, general announcement, FAQ bagi para calon customer yang ingin bergabung dengan perusahaan. Pada modul promosi, perusahaan melakukan aktifitas pemasaran kepada para customer baru, guna menarik minat mereka untuk bergabung dalam memasarkan produk perusahaan PT TDI. Hal ini dilakukan dengan cara meminta pengunjung website untuk memasukkan alamat email-nya. Sehingga nantinya perusahaan akan mengirimkan promosi-promosi perusahaan melalui alamat email tersebut. Pada halaman ini juga disajikan seluruh informasi mengenai barang yang masuk kategori promosi. Setelah tertarik untuk bergabung, para customer dapat memilih menu register yang berfungsi untuk mendaftarkan diri mereka bergabung dengan perusahaan. Setelah melakukan register, pihak perusahaan akan menghubungi dalam waktu 1 x 24 jam untuk konfirmasi. Pada modul general announcement, para customer dapat melihat event yang diadakan perusahaan. Modul ini dapat menarik minat para customer untuk ikut berpartisipasi dalam event tersebut. Keikutsertaan customer akan menjadi peluang bagi perusahaan untuk menarik dealer untuk bergabung menawarkan produk perusahaan. Pada modul FAQ, para customer dapat melihat semua list pertanyaan yang sering diajukan berserta jawabannya. Dari semua pertanyaan tersebut, para customer dapat memperkirakan apa saja keuntungan dan kerugian yang mungkin didapatkan jika bergabung dengan perusahaan. Jadi dengan begitu, modul FAQ ini menjadi faktor pendukung dalam menarik customer baru.

Fase kedua adalah meningkatkan kemampuan untuk menghasilkan keuntungan dari customer yang telah ada (Enhance). Pada website yang diusulkan terdapat modul Transaction, My History dan Point. Pada modul Transaction, para customer dapat melakukan transaksi dengan lebih mudah dan cepat, bahkan dapat melakukan transaksi di mana saja dan kapan pun. Pada menu Transaction ini, para customer dapat melakukan pemesanan (order), pembatalan pemesanan (back order), mengajukan klaim, dan melakukan retur barang. Selain itu, disediakan juga modul history transaction, di mana pada modul ini para customer dapat melihat transaksi-transaksi yang pernah dilakukannya selama ini pada perusahaan, mulai dari pemesanan (order), pembatalan pemesanan (back order), mengajukan klaim, dan melakukan retur barang. Pada menu Point, para customer dapat melihat perolehan poin yang didapat oleh customer tersebut. Biasanya dalam rangka meningkatkan loyalitas dari para customer, perusahaan sering mengadakan event-event reward yang memberikan hadiah kepada para customer atas pengumpulan poin tertentu berdasarkan pada besarnya transaksi yang dilakukannya. Hal ini dapat menarik minat para customer untuk membeli produk perusahaan lebih banyak lagi, guna mendapatkan poin-poin tersebut. 
Fase ketiga yaitu mempertahankan konsumen yang ada (retain). Pada website yang diusulkan terdapat modul Product, Critical \& Sugestion, Question, Private Announcement, Questionnaire, Forum dan Buletin. Pada modul Product ini perusahaan dapat melihat semua produk-produk yang ditawarkan perusahaan, baik produk baru, best seller maupun produk lama. Pada modul Critical \& Sugestion, para customer dapat mengajukan kritik dan saran kepada pihak perusahaan, baik yang berkenaan dengan pemasaran, penjualan, produk, pelayanan dll. Yang nantinya segala informasi tersebut akan ditampung oleh pihak perusahaan sebagai bahan pertimbangan dan acuan bagi pihak perusahaan untuk lebih berkembang. Selain itu, informasi yang diperoleh dapat membantu perusahaan dalam mengidentifikasi segala kekurangan yang terdapat pada perusahaan, yang dapat memberikan ancaman bagi perusahaan kehilangan customer yang selama ini telah menjadi penyalur produk perusahaan. Pada modul Private Announcement, para customer akan memperoleh informasi khusus dari pihak perusahaan, contohnya reminder jatuh tempo piutang, undangan atas event tertentu yang diadakan pihak perusahaan, pemberitahuan mengenai list harga produk perusahaan, produk baru yang dikeluarkan perusahaan, dll. Dengan begitu, para customer akan merasa diperhatikan oleh pihak perusahaan. Pada modul Question, para customer dapat mengajukan pertanyaan-pertanyaan seputar proses bisnis yang selama ini dilakukan kepada pihak perusahaan. Pertanyaan ini akan dijawab oleh pihak perusahaan dalam waktu 1 x 24 jam. Pada modul Questionnaire, perusahaan dapat melakukan survei mengenai segala informasi yang ingin diketahui oleh perusahaan. Dengan begitu, perusahaan dapat memperoleh feedback dari pihak customer berkenaan dengan aktifitas survei yang dilakukan oleh perusahaan. Dari hasil survei tersebut, pihak perusahaan dapat melakukan refleksi diri berdasarkan informasi yang didapat mengenai apa yang menjadi kekurangan dan ancaman dari aktifitas yang dilakukan perusahaan. Pada modul forum dan buletin ini, para customer dapat melihat segala informasi yang disampaikan oleh para customer yang tergabung di dalam website. Selain itu, forum juga dapat digunakan sebagai sarana untuk bertukar pikiran apabila terjadi suatu permasalahan. Bentuk realisasi dari masing-masing fase yang ada dapat terlihat dengan jelas pada Gambar 2 berikut.

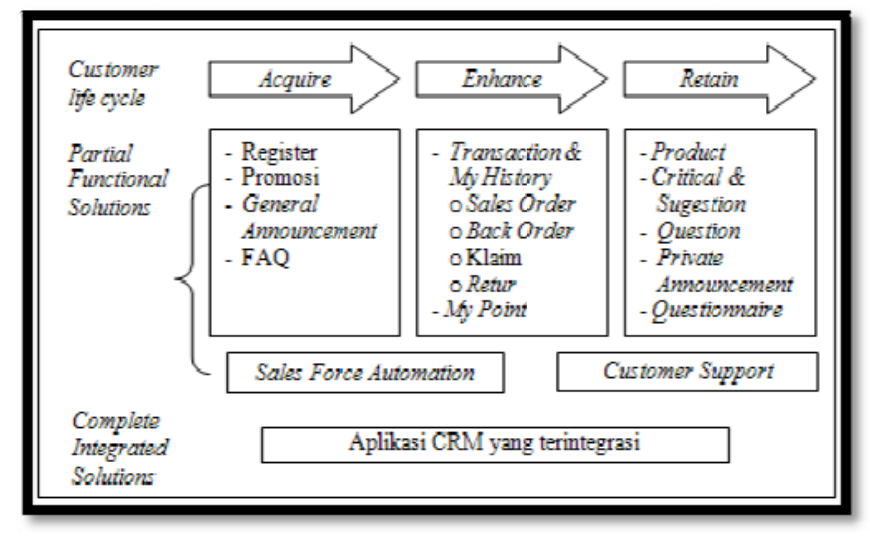

Gambar 2 Arsitektur CRM

Dari alur operasional yang berjalan dalam perusahaan PT TDI dan telah dipetakan dalam bentuk konsep CRM, selanjutnya dapat dibentuk model perancangan database yang dapat mengintegrasikan masing-masing fitur yang akan diimplementasi pada sistem yang berjalan. Tahapan perancangan sistem database ini mengacu pada konsep database life cycle dari pendekatan Connolly and Begg (2010), yang terbagi menjadi beberapa tahapan sebagai berikut:

\section{Database Planning}

Pada tahapan awal ini dilakukan perencanaan realisasi kegiatan dalam tahapan pengembangan database system life cycle secara efektif dan efisien. Dalam tahapan database planning ini mengintegrasikan seluruh strategi sistem informasi dalam organisasi. 
Tahapan awal yang penting dalam database planning adalah secara jelas mendefinisikan mission statement untuk sistem database yang akan dibangun. Mission statement mendefinisikan tujuan utama dari sistem database, guna mengarahkan projek. Pada studi kasus ini, mission statementnya adalah merancang, mengintegrasikan, dan mengelola data yang dibutuhkan untuk mendukung proses operasional yang berlangsung dalam perusahaan dengan mengkolaborasikan konsep Customer Relationship Management (CRM). Setelah terbentuk mission statement, langkah selanjutnya adalah mendefinisikan mission objective yang berfungsi dalam mengidentifikasi kegiatan yang menunjang sistem database. Mission objective-nya sebagai berikut:

1) Mengelola tabel (insert, update, select) pada produk

2) Mengelola tabel (insert, update, select) pada karyawan

3) Mengelola tabel (insert, update, select) pada FAQ

4) Mengelola tabel (insert, update, select) pada klaim

5) Mengelola tabel (insert, update, select) pada customer

6) Mengelola tabel (insert, update, select) pada surat order pemesanan

7) Mengelola tabel (insert, update, select) pada surat jalan

8) Mengelola tabel (insert, update, select) pada surat permintaan pembelian

9) Mengelola tabel (insert, update, select) pada surat pembelian

10) Mengelola tabel (insert, update, select) pada retur

11) Mengelola tabel (insert, update, select) pada backorder

12) Mengelola tabel (insert, update, select) pada retur

13) Mengelola tabel (insert, update, select) pada pembayaran

14) Mengelola tabel (insert, update, select) pada promosi

15) Mengelola tabel (insert, update, select) pada pengumuman

16) Mengelola tabel (insert, update, select) pada point

17) Mengelola tabel (insert, update, select) pada pertanyaan

18) Mengelola tabel (insert, update, select) pada kritik

19) Mengelola tabel (insert, update, select) pada saran

20) Mengelola tabel (insert, update, select) pada private announcement

21) Mengelola tabel (insert, update, select) pada jawaban

22) Mengelola basis data (select) pada laporan pemesanan

23) Mengelola basis data (select) pada laporan pembelian

\section{System Definition}

Spesifikasi lingkup dan boundaries dari sistem database, termasuk dari user view, pengguna, dan area aplikasi pada penelitian ini mencakup proses penjualan, pembelian, persediaan, registrasi customer, registrasi supplier, serta proses pelayanan transaksi secara menyeluruh.

\section{Requirement Collection and Analysis}

Tahapan ini merupakan pengumpulan data dan analisis kebutuhan dari sistem database yang akan diajukan. Setelah dilakukan observasi, ditemukan beberapa klasifikasi data, yaitu: data barang, faktur penjualan, pembelian, supplier, customer, surat jalan, retur, serta pembayaran. Masing-masing data ini akan diintegrasikan ke dalam sistem.

\section{Database Design}

Pada tahap ini dilakukan pembentukan desain yang akan mendukung mission statement dan mission objective sebagai kebutuhan dari sistem database. Tahapan ini terbagi menjadi tiga tahapan utama, yaitu: conceptual database design, logical database design, dan physical database design. 


\section{Conceptual Database Design}

Pada tahap ini dilakukan pembentukan data model yang digunakan dalam perusahaan, terlepas dari aspek fisikal. Tahap ini termasuk dalam tahap awal perancangan, di mana pada tahap ini akan menghasilkan suatu data model yang terbentuk dari dokumen berdasarkan spesifikasi kebutuhan dari pengguna. Tahap konseptual secara keseluruhan terbebas dari detil aturan teknikal, seperti software DBMS, program aplikasi, bahasa pemrograman, platform hardware, ataupun masalah fisikal lainnya. Berikut contoh tahapan yang dilakukan pada level konseptual (Tabel 1):

Tabel 1 Identifikasi Entitas dan Asosiasi Atribut Entitas

\begin{tabular}{llllllc}
\hline Entity Name & \multicolumn{1}{c}{ Attribute } & Description & $\begin{array}{c}\text { Data } \\
\text { Type }\end{array}$ & Length & Null & Multivalued \\
\hline FAQ & IDFAQ & Kode dari FAQ & Integer & 11 & No & No \\
\cline { 2 - 6 } & TopikFAQ & Judul FAQ & Varchar & 255 & No & No \\
\cline { 2 - 6 } & Pertanyaan & $\begin{array}{l}\text { Pertanyaan yang sering } \\
\text { ditanyakan }\end{array}$ & Varchar & 255 & No & No \\
\cline { 2 - 6 } & Jawaban & Jawaban dari pertanyaan & Varchar & 255 & No & No \\
& TanggalProses & Tanggal pemrosesan FAQ & Datetime & - & No & No \\
\hline
\end{tabular}

\section{Logical Database Design}

Setelah melalui tahap konseptual, selanjutnya masuk pada tahap logikal. Pada tahap ini dilakukan pembentukan data model perusahaan berdasarkan pemodelan yang lebih spesifik, tetapi terlepas dari penggunaan jenis DBMS tertentu dan permasalahan fisikal. Tahap ini lebih menekankan pada validasi dan pengetesan dari sisi kebutuhan pengguna. Hal ini dilakukan dengan menggunakan metode normalisasi sebagai teknik untuk mengetes validitas dari model logikal. Berikut data model yang terbentuk dari proses perancangan yang dilakukan (Gambar 3).

\section{Physical Database Design}

Proses selanjutnya adalah pembentukan deskripsi dalam implementasi database pada media penyimpanan; Hal ini digambarkan dalam relasi table dasar, organisasi file, dan index yang digunakan untuk memeperoleh akses yang efisien terhadap data, dan integrity constraint, serta pengukuran keamanan. Berikut contoh pembentukan Database Design Language ( $D B D L$ ) pada tahap perancangan level fisikal:

DBDL Produk

Domain Kode_Produk

Domain Nama_Produk

Domain Jenis_Produk

Domain Ukuran_Produk

Domain Gambar_Produk

Domain Harga_Produk

Produk (

IDProduk
NamaProduk
Jenis
Ukuran
Gambar

\author{
Char,Length 5 \\ Varchar,Length 50 \\ Varchar,Length 30 \\ Varchar,Length 3 \\ Varchar,Length 15 \\ Decimal
}

$\begin{array}{ll}\text { Kode_Produk } & \text { NOT NULL, } \\ \text { Nama_Produk } & \text { NOT NULL, } \\ \text { Jenis_Produk } & \text { NOT NULL, } \\ \text { Ukuran_Produk } & \text { NOT NULL, } \\ \text { Gambar_Produk } & \text { NOT NULL, }\end{array}$




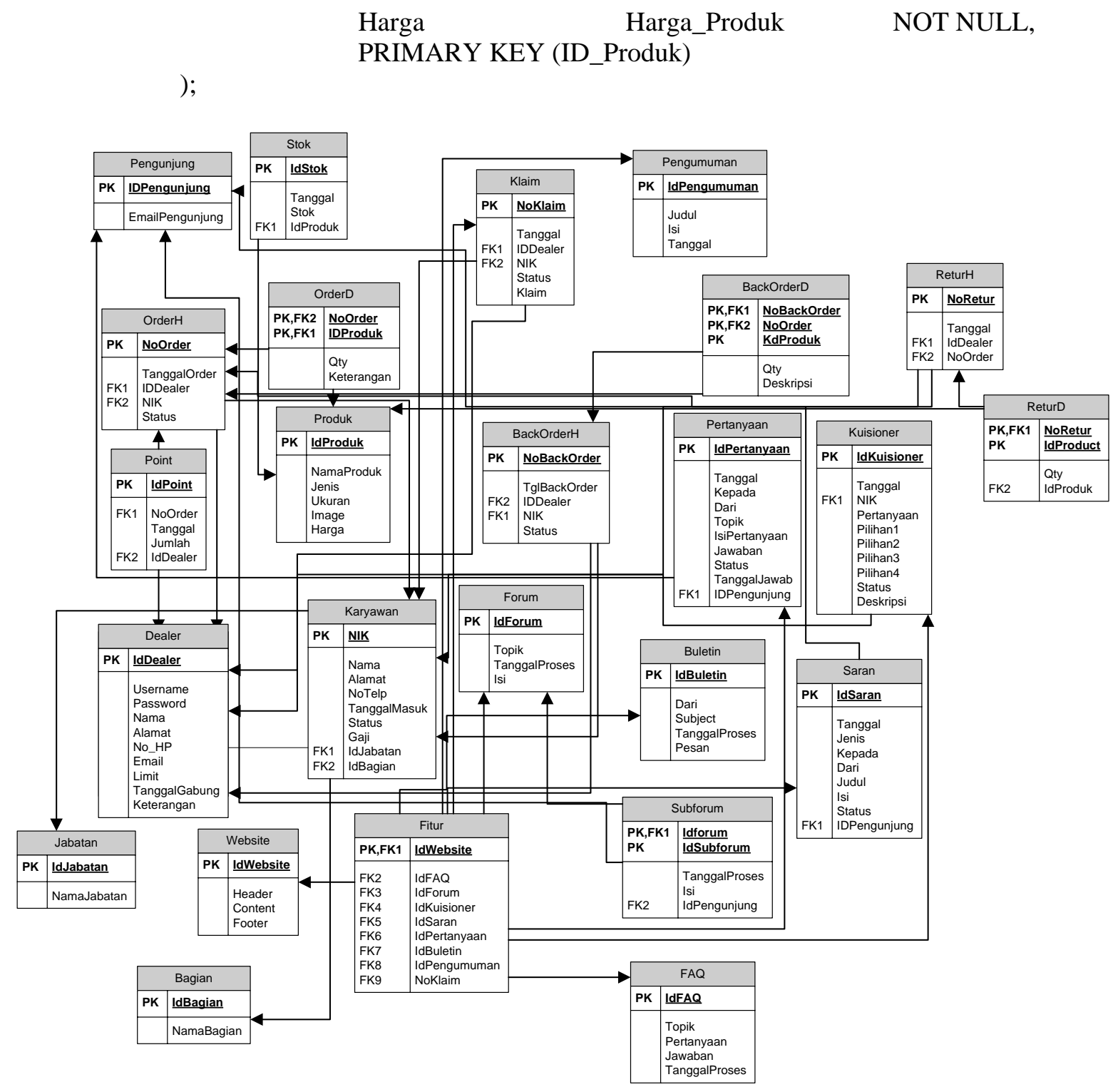

Gambar 3 Entity relationship diagram

\section{DBMS Selection}

Pada tahapan ini dilakukan pemilihan DBMS yang sesuai dengan konsep database yang dirancang. DBMS yang digunakan pada perusahaan ini mengacu pada DBMS Microsoft SQL Server 2008. Hal ini dikarenakan pada sistem yang berjalan perusahaan telah menggunakan platform tersebut, sehingga tidak dilakukan perbandingan dengan DBMS lainnya.

\section{Application Design}

Setelah dilakukan perancangan database, selanjutnya dilakukan perancangan user interface dan program aplikasi yang digunakan sebagai eksternal view dalam pemrosesan data dalam database. Berikut contoh tampilan layar yang dihasilkan (Gambar 4): 


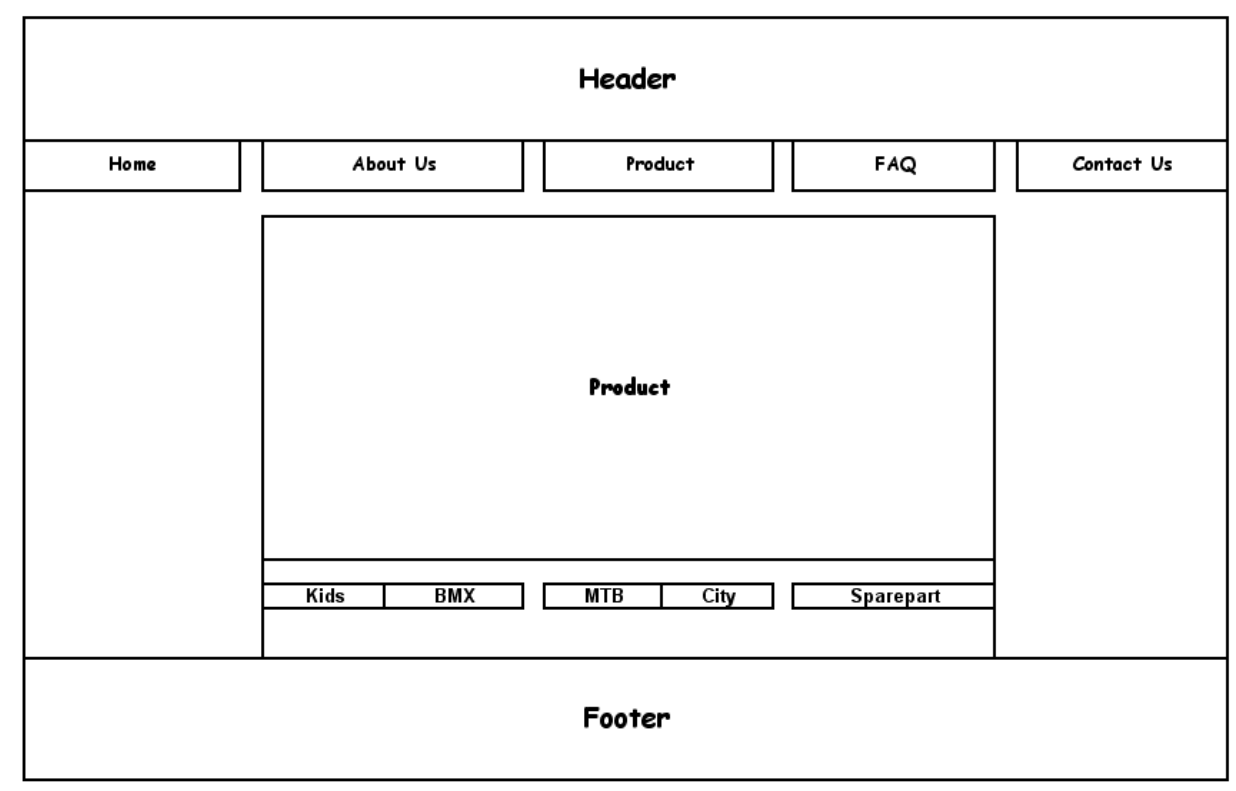

Gambar 4 Tampilan layar

\section{Prototyping}

Pada tahap ini dilakukan pembentukan model kerja dari sistem database, yang memungkinkan pengguna dalam memvisualisasi dan mengevaluasi bagaimana sistem bekerja. Tujuan utama dalam tahap ini adalah mengembangkan prototype sistem database yang memungkinkan pengguna untuk menggunakan prototype dalam mengidentifikasikan fitur sistem yang sesuai dan jika memungkinkan memberikan masukan untuk pengembangan lebih lanjut maupun fitur baru yang dapat diajukan. Tahapan prototyping ini dilakukan dengan membandingkan data model yang terbentuk dengan prosedur kerja yang berjalan dan disesuaikan dengan tampilan layar yang dihasilkan. Strategi prototyping ini terbagi menjadi 2 (dua) bagian, yaitu requirements prototyping dan evolutionary prototyping. Pada requirement prototyping dilakukan dengan menggunakan prototipe untuk menentukan kebutuhan dari sistem database yang diajukan, dan ketika requirement telah terpenuhi, maka prototype akan dihilangkan. Sedangkan pada evolutionary prototyping, prototype tidak dihilangkan melainkan dapat dijadikan sebagai pengembangan lebih lanjut dari sistem. Pada penelitian ini prototyping dilakukan dengan model evolutionary prototyping yang memungkinkan prototype yang dihasilkan tetap disimpan untuk kebutuhan selanjutnya.

\section{Implementation}

Tahap perancangan dilanjutkan dengan tahap implementasi database dan program aplikasi. Implementasi database dilakukan menggunakan DDL pada DBMS yang digunakan atau GUI, yang menyediakan kesamaan fungsional dengan DDL. Sedangkan implementasi program aplikasi menggunakan software aplikasi 3GL atau 4GL, yang berfungsi sebagai bagian dalam transaksi database, dengan mengimplementasikan fungsi DML pada target DBMS. Selain itu, pada system ini juga dirancang sistem keamanan dan integritas pada sistem yang terbentuk.

\section{Data Conversion and Loading}

Pada tahapan ini dilakukan pemindahan data dari sistem yang lama ke sistem baru, dan jika memungkinkan dilakukan konversi dari aplikasi yang berjalan ke database baru. Tahapan ini 
dilakukan jika sistem yang baru akan menggantikan sistem yang lama. Oleh karena itu, pada kasus ini tidak dilakukan proses konversi data.

\section{Testing}

Setelah melakukan pembentukan sistem, selanjutnya adalah proses testing guna mengecek kesalahan dan validasi apakah ada requirement yang tidak sesuai dengan pengguna sebelum dijalankan secara live. Secara ideal proses testing ini tentunya melibatkan seluruh pengguna sistem agar mengetahui secara pasti apakah sistem yang dibentuk sudah sesuai dengan kebutuhan pengguna. Berikut kriteria evaluasi sistem yang perlu dilakukan saat testing: (1) learnability, yaitu seberapa lama pengguna baru dapat produktif dengan menggunakan sistem baru; (2) performance, yaitu seberapa baik sistem merespon sesuai dengan pekerjaan pengguna; (3) robustness, yaitu seberapa besar toleransi sistem jika pengguna salah; (4) recoverability, yaitu seberapa baik sistem dalam melakukan recovery dari error yang terjadi; (5) adaptability, yaitu bagaimana sistem dapat disatukan dalam model kerja.

\section{Operational Maintenance}

Pada tahapan ini dilakukan implementasi secara keseluruhan. Sistem ini secara berkesinambungan dimonitor dan dimaintain guna mencegah turunnya performa kerja. Namun, secara normal DBMS memiliki utilitas yang dapat membantu dalam mengatur database, termasuk di dalamnya kemampuan dalam monitoring yang dapat memberikan informasi mengenai penggunaan database, efisiensi locking, serta strategi eksekusi query. Dari seluruh informasi yang tersedia dapat membantu DBA dalam melakukan tuning ke dalam sistem agar dapat meningkatkan performa sistem. Dalam kasus ini, perlu dilakukan pengecekan konsistensi data secara periodic pada operasional yang berjalan, sehingga tidak ditemukan waktu delay ketika transaksi terjadi.

\section{PENUTUP}

Setelah dilakukan proses analisis dan perancangan terhadap sistem pada objek penelitian PT TDI, maka dapat ditarik beberapa simpulan, yaitu: (1) Model database yang dihasilkan dapat membantu perusahaan dalam menerapkan sistem CRM yang terpadu dengan layanan transaksi yang dilakukan berbasiskan web, sehingga customer dapat dengan mudah berinteraksi dengan perusahaan tanpa adanya batasan waktu dan tempat; (2) Melalui rancangan aplikasi yang terbentuk, aliran informasi dari perusahaan ke customer menjadi lebih efisien dan efektif karena customer dapat secara mandiri mengakses seluruh informasi yang berkaitan dengan perusahaan; (3) konsep customer touching application dapat dengan mudah diterapkan karena dengan bentuk rancangan sistem yang dibangun, memungkinkan customer melayani dirinya sendiri secara personal; (4) infrastruktur yang dirancang menggunakan platform yang disesuaikan dengan operasional yang berjalan dalam perusahaan. Hal ini memudahkan dalam tahap implementasi yang dilakukan.

\section{DAFTAR PUSTAKA}

Belanger, F., \& Slyke, C. V. (2012). Information Systems for Business. New Jersey: John Wiley \& Sons.

Chaffey, D. (2000). Internet Marketing: Strategy, Implementation and Practice. London: Pearson Education. 
Connolly, T. M., \& Begg, C. E. (2010). Database Systems: A Practical Approach to Design, Implementation, and Management. Boston: Pearson Education.

Hellerstein, J. M., Stonebraker, M., \& Hamilton, J. (2007). Architecture of a Database System. Foundations and Trends in Databases, 141-259.

Kalakota, R., \& Robinson, M. (2001). E-Business 2.0: Roadmap for Success . Boston: Addison Wesley.

Motiwalla, L. F., \& Thompson, J. (2009). Enterprise Systems For Management. New Jersey: Pearson Education. 